\title{
BMJ Open Risk of pleural empyema in patients with schizophrenia: a nationwide propensity-matched cohort study in Taiwan
}

\author{
Te-Chun Shen, ${ }^{1,2}$ Chia-Hung Chen, ${ }^{1}$ Yu-Jhen Huang, ${ }^{3}$ Cheng-Li Lin, ${ }^{4}$ \\ Ting-Chang Chang, ${ }^{5}$ Chih-Yen Tu, ${ }^{1,6}$ Te-Chun Hsia, ${ }^{1}$ Chuen-Ming Shih, ${ }^{1,6}$ \\ Wu-Huei Hsu, ${ }^{1,6}$ Fung-Chang Sung ${ }^{4,7}$
}

To cite: Shen T-C, Chen C-H, Huang Y-J, et al. Risk of pleural empyema in patients with schizophrenia: a nationwide propensity-matched cohort study in Taiwan. BMJ Open 2018;8:e021187. doi:10.1136/ bmjopen-2017-021187

- Prepublication history for this paper is available online To view these files, please visit the journal online (http://dx.doi org/10.1136/bmjopen-2017021187).

C-MS and F-CS contributed equally.

Received 15 December 2017 Revised 30 April 2018 Accepted 14 May 2018
Check for updates

For numbered affiliations see end of article.

Correspondence to Professor Fung-Chang Sung; fcsung1008@yahoo.com

\section{ABSTRACT}

Objective Thoracic infection and pneumonia are prevalent in patients with schizophrenia; however, it is unclear whether patients with schizophrenia are at an increased risk of developing pleural empyema.

Design A retrospective cohort study with propensitymatched cohorts with and without schizophrenia.

Setting Using the National Health Insurance Research Database of Taiwan.

Participants We identified 55888 patients with schizophrenia newly diagnosed in 2000-2011 and same number of individuals without schizophrenia as the comparison cohort, frequency matched by propensity scores estimated using age, sex, occupation, income, urbanisation, year of diagnosis and comorbidities.

Primary outcome measures We assessed incident pleural empyema by the end of 2011 and used the Cox proportional hazards model to calculate the schizophrenia cohort to comparison cohort HR of pleural empyema. Results The overall incidence of pleural empyema was 2.44-fold greater in the schizophrenia cohort than in the comparison cohort (4.39vs1.80 per 10000 personyears), with an adjusted $\mathrm{HR}$ of $2.87(95 \% \mathrm{Cl} 2.14$ to 3.84$)$. Stratified analyses by age, sex, occupation, income, urbanisation and comorbidity revealed significant hazards for pleural empyema associated with schizophrenia in all subgroups.

Conclusions Patients with schizophrenia are at an increased risk of developing pleural empyema and require greater attention and appropriate support.

\section{INTRODUCTION}

Patients with pleural empyema require prompt and timely treatments, such as antibiotic therapy, pleural space drainage, intrapleural fibrinolysis and/or surgery. ${ }^{12}$ Approximately 60000 cases of pleural empyema are diagnosed annually in the USA. ${ }^{3}$ The condition is more prevalent in Taiwan, with the incidence rates ranging from 0.96 to 8.19 per 10000 person-years. ${ }^{4-6}$ Alcoholism, drug abuse, diabetes mellitus, immunocompromised status, neoplasm and
Strengths and limitations of this study

- This is the first nationwide propensity scorematched cohort study to evaluate the risk of pleural empyema in patients with schizophrenia.

- The National Health Insurance programme of Taiwan have covered $>99 \%$ of 23.74 million people.

- Universal coverage reduces barriers to healthcare access for all citizens.

- The International Classification of Diseases, Ninth Revision, Clinical Modification algorithm was used to define diseases and an ad hoc committee was in charge to monitor the claims data to prevent errors and violation of confidentiality.

- The database does not provide detailed information on lifestyles and other psychosocial and environmental factors.

- Relevant clinical variables such as serum laboratory data and image reports were unavailable in the database.

pre-existent pulmonary disease or pleural effusion are risk factors for the development of pleural empyema. ${ }^{78}$ Patients with pleural empyema and comorbid with chronic illness are at a poorer prognosis and a greater risk of mortality. ${ }^{910}$

Schizophrenia is a severe mental disorder, characterised by profound disruptions in thinking, affecting language, perception and the sense of self. ${ }^{11}$ The hallmark symptom of schizophrenia is psychosis, such as experiencing auditory hallucinations and delusions. ${ }^{12}$ Approximately $0.3 \%-0.7 \%$ of individuals are affected by schizophrenia during their lifetime, and thus, schizophrenia affects $>21$ million people worldwide. ${ }^{13}$ People with schizophrenia are at a markedly increased risk of premature death. Despite elevated rates of suicide and other unnatural causes of death, most of the excess mortality 
Table 1 Baseline characteristics compared between cohorts with and without schizophrenia

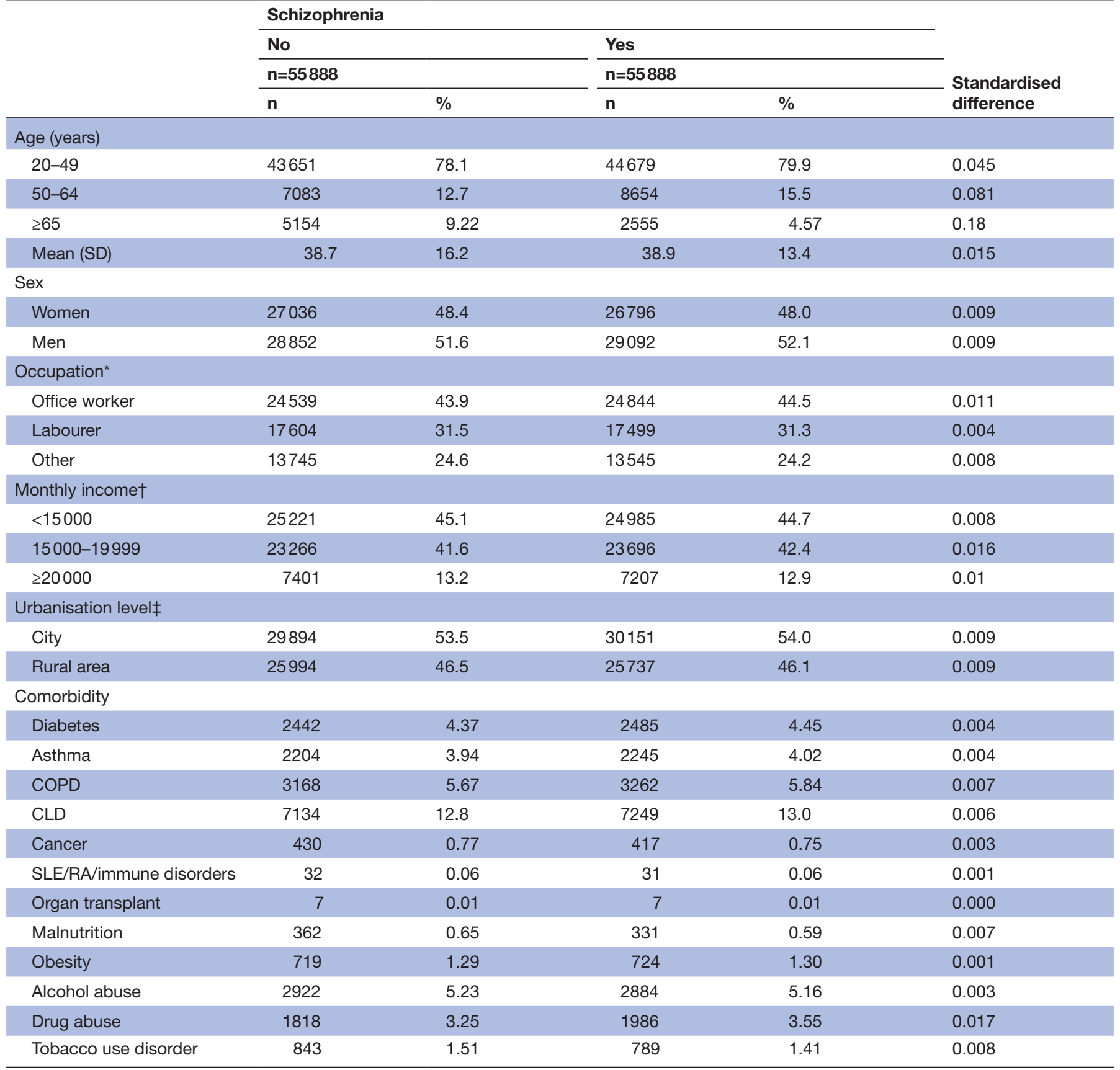

*Other occupations include primarily retired, unemployed and low-income populations.

†1 new Taiwan dollar is equal to 0.03 US dollar.

$\ddagger$ The urbanisation level is categorised by the population density of the residential area into two levels: city and rural area.

CLD, chronic liver disease and cirrhosis; COPD, chronic obstructive pulmonary disease; RA, rheumatoid arthritis; SLE, systemic lupus erythematosus.

has been attributed to cardiovascular disease, respiratory disease and other natural causes. ${ }^{14}$

Patients with schizophrenia have been associated with a higher risk of thoracic infections. ${ }^{15-17}$ The risk of having pneumonia is threefold greater in patients with schizophrenia than in general population. ${ }^{16}{ }^{18}$ Unhealthy lifestyle, lack of self-care, poorer physical circumstances and health-risk activities may contribute to this condition. ${ }^{13}$ Furthermore, patients with schizophrenia suffering from these infections may have poorer clinical outcomes, such as acute respiratory failure, the use of mechanical ventilation, intensive care unit admission and hospital death. ${ }^{16}$ Thoracic infection and pneumonia greatly increase morbidity and mortality in patients with schizophrenia and seriously threaten the health of these patients. However, the association between schizophrenia and the occurrence of pleural empyema, an advanced and specific thoracic infection, remains unclear. 


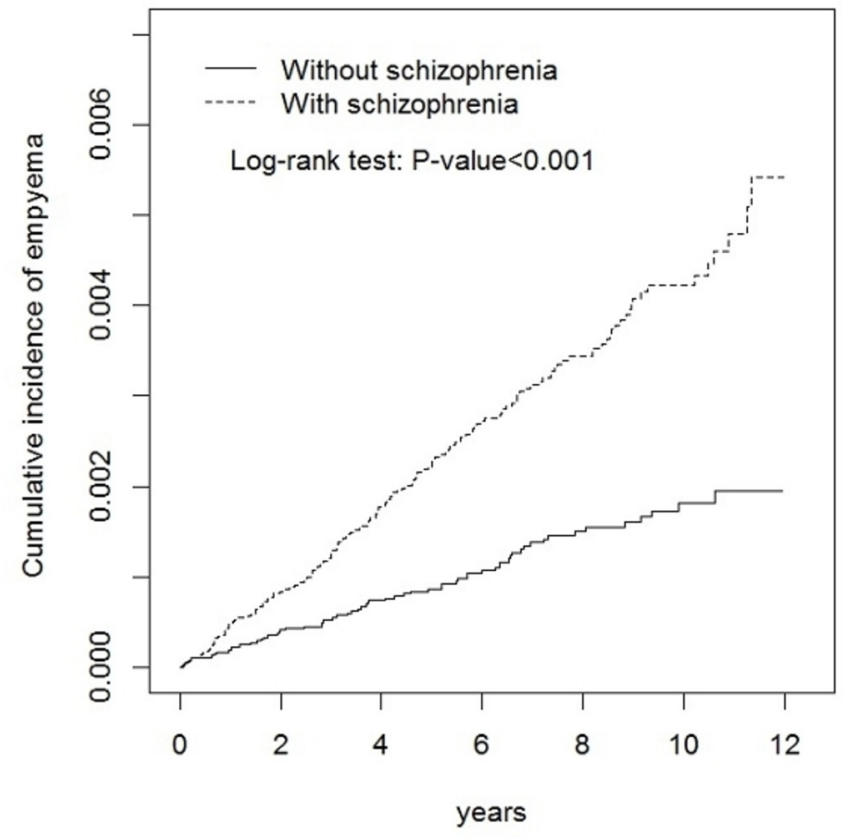

Figure 1 Cumulative incidence of pleural empyema in the schizophrenia cohort (dashed line) and the comparison cohort (solid line).

The National Health Insurance Research Database (NHIRD) in Taiwan is a nationwide database containing the medical claims data of 23 million residents. These reliable data have been used in studies on various disorders, including schizophrenia and pleural empyema. ${ }^{60-22}$ The present study aims to investigate whether patients with schizophrenia are at an increased risk of subsequent occurrence of pleural empyema. In addition to estimate the incidence of pleural empyema in persons with and without schizophrenia, we also compared the 30-day mortality from pleural empyema between the two cohorts.

\section{MATERIALS AND METHODS \\ Data source}

The universal health insurance of Taiwan covers $>99 \%$ of the Taiwanese population. Information on demographic status of insured people and their medical services received were available in the NHIRD obtained from the National Health Research Institutes. Patient identifiers were re-encoded before the release of NHIRD to protect the patient privacy.

\section{Study population}

Pleural empyema is one of the diseases among 30 categories of catastrophic illnesses classified in the insurance system, requiring long-term and/or extensive care, similar to cancers, end-stage major organ diseases, systemic autoimmune diseases and major mental disorders. After a careful peer-review process, patients registered with a catastrophic illness certificate are eligible for reduced financial burden for healthcare.

For the present study, we used a subset data of NHIRD, the Longitudinal Health Insurance Database 2000
(LHID2000), which contains health data of 1 million people randomly selected from 23 million people. From the database, we identified patients with schizophrenia aged 20 years and older newly diagnosed in 2000-2011 (International Classification of Diseases, Ninth Revision, Clinical Modification (ICD-9-CM) code 295), without the history of pleural empyema (ICD-9-CM code 510) as the schizophrenia cohort. The comparison cohort were randomly selected from individuals without schizophrenia and pleural empyema from the LHID2000 file, using a 1:1 ratio, frequency matched by propensity scores. The propensity score was estimated to reduce bias from baseline variables, including age, sex, occupation, monthly income, urbanisation level and comorbidities of diabetes (ICD-9-CM code 250), asthma (ICD-9-CM code 493), chronic obstructive pulmonary disease (COPD) (ICD-9-CM code 496), chronic liver disease and cirrhosis (CLD) (ICD-9-CM code 571), cancer (ICD-9-CM codes 140-208), systemic lupus erythematosus (SLE)/rheumatoid arthritis (RA)/immune diseases (ICD-9-CM codes 710.0, 714.0, 279), organ transplant (ICD-9-CM code V42), malnutrition (ICD-9-CM codes 260-269), obesity (ICD-9-CM code 278.0), alcohol abuse (ICD-9-CM codes 291, 303, 305.0), drug abuse (ICD-9-CM codes 292, 304, $305.2,305.9$ ) and tobacco use disorder (ICD-9-CM code $305.1)$.

\section{Patient and public involvement}

This retrospective cohort study used the secondary data of insurance claims with anonymised identifications. Therefore, we considered that patients and public were not involved.

\section{Outcome}

The main outcome of this study was pleural empyema. Person-years indicated the sum of the follow-up time for all participants, and the follow-up time was defined as the time from the index date to the diagnosis of pleural empyema, death, withdrawal from the insurance or the end of 2011.

\section{Statistical analysis}

The two study groups were matched by the propensity scores, and the standardised difference was used to quantify differences in means or prevalence rates between schizophrenia and comparison cohorts for continuous or categorical variables, respectively. A standardised difference of 0.1 or less indicated a negligible difference between two cohorts. ${ }^{23}$ The incidence rate of pleural empyema was estimated per 10000 person-years. We used Poisson regression analysis to calculate the patients with schizophrenia to controls incidence rate ratio (IRR). The Kaplan-Meier method was then used to calculate and plot the cumulative incidence of pleural empyema for each cohort and the difference between the two curves was examined using log-rank test. Multivariable Cox proportional hazards regression analysis was used to estimate the adjusted HR (aHR) and 95\% CI for the 
Table 2 Incidence of pleural empyema, IRR and aHR measured for pooled study population by study cohort, sociodemographic status and comorbidities

\begin{tabular}{|c|c|c|c|c|c|}
\hline & Event & PY & Rate† & $\begin{array}{l}\text { IRR } \\
(95 \% \mathrm{CI})\end{array}$ & $\begin{array}{l}\text { aHR } \\
(95 \% \mathrm{Cl})\end{array}$ \\
\hline \multicolumn{6}{|l|}{ Schizophrenia } \\
\hline No & 67 & 371984 & 1.80 & 1.00 & 1.00 \\
\hline Yes & 164 & 373435 & 4.39 & $2.44(1.83 \text { to } 3.24)^{\star \star \star}$ & $2.87(2.14 \text { to } 3.84)^{\star \star \star}$ \\
\hline \multicolumn{6}{|l|}{ Age (years) } \\
\hline $20-49$ & 126 & 604297 & 2.09 & 1.00 & 1.00 \\
\hline $50-64$ & 65 & 97993 & 6.63 & $3.19(2.36 \text { to } 4.30)^{\star \star \star}$ & $2.86(2.09 \text { to } 3.93)^{\star \star \star}$ \\
\hline$\geq 65$ & 40 & 43129 & 9.27 & $4.46(3.13 \text { to to } 6.37)^{\star \star \star}$ & $3.45(2.29 \text { to } 5.19)^{\star \star \star}$ \\
\hline \multicolumn{6}{|l|}{ Sex } \\
\hline Women & 52 & 360369 & 1.44 & 1.00 & 1.00 \\
\hline Men & 179 & 385050 & 4.65 & $3.22(2.37 \text { to } 4.39)^{\star \star \star}$ & $3.52(2.57 \text { to } 4.82)^{\star \star \star}$ \\
\hline \multicolumn{6}{|l|}{ Occupation§ } \\
\hline Office worker & 79 & 328927 & 2.40 & 1.00 & 1.00 \\
\hline Labourer & 75 & 232762 & 3.22 & 1.34 (0.98 to 1.84$)$ & 0.94 (0.67 to 1.33) \\
\hline Other & 77 & 183730 & 4.19 & $1.75(1.28 \text { to } 2.39)^{\star \star \star}$ & 1.19 (0.82 to 1.71$)$ \\
\hline \multicolumn{6}{|l|}{ Monthly incomeף } \\
\hline$<15000$ & 113 & 328597 & 3.44 & $2.00(1.20 \text { to } 3.33)^{\star \star}$ & $1.92(1.10 \text { to } 3.33)^{\star}$ \\
\hline $15000-19999$ & 101 & 318118 & 3.17 & $1.84(1.10 \text { to } 3.08)^{\star}$ & $1.97(1.15 \text { to } 3.36)^{\star}$ \\
\hline$\geq 20000$ & 17 & 98704 & 1.72 & 1.00 & 1.00 \\
\hline \multicolumn{6}{|c|}{ Urbanisation level†† } \\
\hline City & 97 & 399858 & 2.43 & 1.00 & 1.00 \\
\hline Rural area & 134 & 345561 & 3.88 & $1.60(1.23 \text { to } 2.08)^{\star \star \star}$ & $1.46(1.12 \text { to } 1.90)^{\star *}$ \\
\hline \multicolumn{6}{|l|}{ Comorbidity } \\
\hline \multicolumn{6}{|l|}{ Diabetes } \\
\hline No & 197 & 718779 & 2.74 & 1.00 & 1.00 \\
\hline Yes & 34 & 26641 & 12.8 & $4.67(3.24 \text { to } 6.73)^{\star \star \star}$ & $2.62(1.77 \text { to } 3.87)^{\star \star \star}$ \\
\hline \multicolumn{6}{|l|}{ Asthma } \\
\hline No & 202 & 719903 & 2.81 & 1.00 & 1.00 \\
\hline Yes & 29 & 25516 & 11.4 & $4.06(2.75 \text { to } 5.99)^{\star \star \star}$ & $1.98(1.27 \text { to } 3.07)^{\star *}$ \\
\hline \multicolumn{6}{|l|}{ COPD } \\
\hline No & 182 & 707738 & 2.57 & 1.00 & 1.00 \\
\hline Yes & 49 & 37681 & 13.0 & $5.07(3.69 \text { to } 6.95)^{\star \star \star}$ & $2.01(1.38 \text { to } 2.95)^{\star \star *}$ \\
\hline \multicolumn{6}{|l|}{ CLD } \\
\hline No & 186 & 655200 & 2.84 & 1.00 & 1.00 \\
\hline Yes & 45 & 90219 & 4.99 & $1.76(1.27 \text { to } 2.43)^{\star \star \star}$ & 1.00 (0.71 to 1.42$)$ \\
\hline \multicolumn{6}{|l|}{ Cancer } \\
\hline No & 228 & 741180 & 3.08 & 1.00 & \\
\hline Yes & 3 & 4239 & 7.08 & 2.30 (0.74 to 7.19$)$ & \\
\hline \multicolumn{6}{|c|}{ SLE/RA/immune disorders } \\
\hline No & 231 & 745075 & 3.10 & 1.00 & \\
\hline Yes & 0 & 345 & 0.00 & - & \\
\hline \multicolumn{6}{|c|}{ Organ transplant } \\
\hline No & 231 & 745312 & 3.10 & 1.00 & \\
\hline Yes & 0 & 107 & 0.00 & - & \\
\hline
\end{tabular}


Table 2 Continued

\begin{tabular}{|c|c|c|c|c|c|}
\hline & Event & PY & Rate† & $\begin{array}{l}\text { IRR } \\
(95 \% \mathrm{Cl}) \\
\end{array}$ & $\begin{array}{l}\text { aHR‡ } \\
(95 \% \mathrm{Cl})\end{array}$ \\
\hline \multicolumn{6}{|c|}{ Malnutrition } \\
\hline No & 223 & 741266 & 3.01 & 1.00 & 1.00 \\
\hline Yes & 8 & 4154 & 19.3 & $6.38(3.15 \text { to } 12.9)^{\star \star \star}$ & $3.60(1.76 \text { to } 7.36)^{\star \star \star}$ \\
\hline \multicolumn{6}{|c|}{ Obesity } \\
\hline No & 229 & 737942 & 3.10 & 1.00 & \\
\hline Yes & 2 & 7478 & 2.67 & 0.86 (0.21 to 3.46$)$ & \\
\hline \multicolumn{6}{|c|}{ Alcohol abuse } \\
\hline No & 209 & 714370 & 2.93 & 1.00 & 1.00 \\
\hline Yes & 22 & 31049 & 7.09 & $2.42(1.56 \text { to } 3.77)^{\star \star \star}$ & $1.74(1.10 \text { to } 2.74)^{\star}$ \\
\hline \multicolumn{6}{|c|}{ Drug abuse } \\
\hline No & 220 & 724902 & 3.03 & 1.00 & \\
\hline Yes & 11 & 20517 & 5.36 & 1.77 (0.96 to 3.24$)$ & \\
\hline \multicolumn{6}{|c|}{ Tobacco use disorder } \\
\hline No & 227 & 739856 & 3.07 & 1.00 & \\
\hline Yes & 4 & 5564 & 7.19 & 2.37 (0.88 to 6.39$)$ & \\
\hline
\end{tabular}

${ }^{*} \mathrm{p}<0.05,{ }^{\star *} \mathrm{p}<0.01,{ }^{* * *} \mathrm{p}<0.001$.

†Incidence rate per $10000 \mathrm{PY}$.

¥Multivariable analysis controlling for age, sex, occupation, income, urbanisation and comorbidities of diabetes, asthma, COPD, CLD, malnutrition and alcohol abuse.

§Other occupations include primarily retired, unemployed and low-income populations.

I1 new Taiwan dollar is equal to 0.03 US dollar.

††The urbanisation level is categorised by the population density of the residential area into two levels: city and rural area.

CLD, chronic liver disease and cirrhosis; COPD, chronic obstructive pulmonary disease; IRR, incidence rate ratio; PY, person-years; RA,

rheumatoid arthritis; SLE, systemic lupus erythematosus.

two groups. The multivariable model included variables of age, sex, occupation, monthly income, urbanisation level and comorbidities of diabetes, asthma, COPD, CLD, malnutrition and alcohol abuse. Data analysis for this study was performed using SAS statistical software (V.9.4 for Windows; SAS Institute Cary, North Carolina, USA). Statistical significance was determined at $\mathrm{p}<0.05$.

\section{RESULTS}

Table 1 shows that schizophrenia and comparison cohorts were similar in distributions of baseline demographics and comorbidities with mean ages of 38.9 and 38.7 years, respectively.

After a mean follow-up time of 6.7years in both cohorts, figure 1 shows that the cumulative incidence of pleural empyema was $0.34 \%$ higher in the schizophrenia cohort than in the comparison cohort. The incidence was 2.4-fold greater in patients with schizophrenia than in comparisons (4.39 vs 1.80 per 10000 person-years), with an IRR of 2.44 (95\% CI 1.83 to 3.24) or an aHR of 2.87 (95\% CI 2.14 to 3.84) (table 2). The pooled data showed that the overall incidence increased with age, and higher in men than in women. Study population of low income and living in rural area were at higher risk of empyema. Individuals with comorbidities are also at increased risk of pleural empyema, including those with diabetes
(aHR 2.62, 95\% CI 1.77 to 3.87), asthma (aHR 1.98, 95\% CI 1.27 to 3.07 ), COPD (aHR 2.01, 95\% CI 1.38 to 2.95), malnutrition (aHR 3.60, 95\% CI 1.76 to 7.36 ) and alcohol abuse (aHR 1.74, 95\% CI 1.10 to 2.74 ).

Table 3 shows the incident empyema developed in the two cohorts by demographic status and comorbidity status. The incidence rates in each stratum were greater in the schizophrenia subgroups than in the comparison subgroups. The schizophrenia group to the comparison group IRRs and aHRs were significant for all strata. Significant IRRs ranged from 1.51 to 3.63 and significant aHRs ranged from 2.45 to 3.70. Comorbidity increased the incidence of pleural empyema in both cohorts for 3.74 and 3.51 per 10000 person-years, respectively. The schizophrenia group to comparison group aHR showed a relatively greater impact for study individuals without comorbidities than those with comorbidity.

Table 4 shows a lower 30 -day mortality rate from pleural empyema for the schizophrenic cohort than for the comparison cohort $(6.71 \%$ vs $8.96 \%)$, with an adjusted OR of 0.95 (95\% CI 0.30 to 3.01 ).

\section{DISCUSSION}

To the best of our knowledge, this is the first propensity-matched cohort study using population data to evaluate the risk of developing pleural empyema in patients 
Table 3 Incidence of pleural empyema and schizophrenia cohort to comparison cohort IRR and aHR

\begin{tabular}{|c|c|c|c|c|c|c|c|c|}
\hline & \multicolumn{6}{|c|}{ Schizophrenia } & \multirow[b]{3}{*}{ IRR (95\% CI) } & \multirow[b]{3}{*}{ aHR‡ $(95 \% \mathrm{Cl})$} \\
\hline & \multicolumn{3}{|l|}{ No } & \multicolumn{3}{|l|}{ Yes } & & \\
\hline & Event & PY & Rate† & Event & PY & Rate† & & \\
\hline \multicolumn{9}{|l|}{ Age (years) } \\
\hline $20-49$ & 30 & 297238 & 1.01 & 96 & 307059 & 3.13 & $3.10(2.06 \text { to } 4.67)^{\star \star \star}$ & $2.77(1.84 \text { to } 4.18)^{\star \star \star}$ \\
\hline $50-64$ & 17 & 45162 & 3.76 & 48 & 52831 & 9.09 & $2.41(1.39 \text { to } 4.19)^{\star \star}$ & $2.55(1.45 \text { to } 4.49)^{\star \star}$ \\
\hline$\geq 65$ & 20 & 29584 & 6.76 & 20 & 13546 & 14.8 & $2.15(1.16 \text { to } 3.99)^{*}$ & $2.68(1.43 \text { to } 5.05)^{\star \star}$ \\
\hline \multicolumn{9}{|l|}{ Sex } \\
\hline Women & 12 & 182640 & 0.66 & 40 & 177729 & 2.25 & $3.43(1.80 \text { to } 6.53)^{\star \star \star}$ & $3.70(1.93 \text { to } 7.11)^{\star \star \star}$ \\
\hline Men & 55 & 189345 & 2.90 & 124 & 195706 & 6.34 & $2.18(1.59 \text { to } 2.99)^{\star \star \star}$ & $2.63(1.90 \text { to } 3.65)^{\star \star \star}$ \\
\hline \multicolumn{9}{|l|}{ Occupation§ } \\
\hline Office worker & 20 & 164783 & 1.21 & 59 & 164144 & 3.59 & $2.99(1.80 \text { to } 4.96)^{\star \star \star}$ & $3.05(1.83 \text { to } 5.11)^{\star \star \star}$ \\
\hline Labourer & 28 & 115910 & 2.42 & 47 & 116852 & 4.02 & $1.67(1.04 \text { to } 2.66)^{*}$ & $2.50(1.53 \text { to } 4.08)^{\star \star \star}$ \\
\hline Other & 19 & 91291 & 2.08 & 58 & 92439 & 6.27 & $3.01(1.79 \text { to } 5.05)^{\star \star \star}$ & $3.41(1.97 \text { to } 5.93)^{\star \star \star}$ \\
\hline \multicolumn{9}{|l|}{ Monthly incomef } \\
\hline$<15000$ & 28 & 162081 & 1.73 & 85 & 166516 & 5.10 & $2.95(1.93 \text { to } 4.53)^{\star \star \star}$ & $3.20(2.07 \text { to } 4.94)^{\star \star \star}$ \\
\hline 15000-19999 & 35 & 158330 & 2.21 & 66 & 159788 & 4.13 & $1.87(1.24 \text { to } 2.82)^{\star \star}$ & $2.49(1.62 \text { to } 3.82)^{\star \star \star}$ \\
\hline$\geq 20000$ & 4 & 51573 & 0.78 & 13 & 47131 & 2.76 & $3.63(1.18 \text { to } 11.1)^{*}$ & $3.64(1.17 \text { to } 11.4)^{*}$ \\
\hline \multicolumn{9}{|c|}{ Urbanisation level†† } \\
\hline City & 24 & 199255 & 1.20 & 73 & 200604 & 3.64 & $3.03(1.91 \text { to } 4.80)^{\star \star \star}$ & $3.67(2.29 \text { to } 5.90)^{\star \star \star}$ \\
\hline Rural area & 43 & 172729 & 2.49 & 91 & 172832 & 5.27 & $2.11(1.47 \text { to } 3.04)^{\star \star \star}$ & $2.45(1.69 \text { to } 3.56)^{\star \star \star}$ \\
\hline \multicolumn{9}{|l|}{ Comorbiditył‡ } \\
\hline No & 26 & 283934 & 0.92 & 96 & 276098 & 3.48 & $3.81(2.47 \text { to } 5.87)^{\star \star \star}$ & $3.73(2.42 \text { to } 5.76)^{\star \star \star}$ \\
\hline Yes & 41 & 88050 & 4.66 & 68 & 97338 & 6.99 & $1.51(1.02 \text { to } 2.22)^{\star}$ & $2.27(1.50 \text { to } 3.42)^{\star \star \star}$ \\
\hline
\end{tabular}

${ }^{*} \mathrm{p}<0.05,{ }^{* *} \mathrm{p}<0.01,{ }^{* * *} \mathrm{p}<0.001$.

†Incidence rate per $10000 \mathrm{PY}$.

†Multivariable analysis controlling for age, sex, occupation, income, urbanisation and comorbidities of diabetes, asthma, chronic obstructive pulmonary disease, chronic liver disease and cirrhosis, malnutrition and alcohol abuse.

$\S$ Other occupations include primarily retired, unemployed and low-income populations.

I1 new Taiwan dollar is equal to 0.03 US dollar.

$\dagger_{\dagger}$ The urbanisation level is categorised by the population density of the residential area into two levels: city and rural area.

¥¥Individuals with any comorbidity of diabetes, asthma, chronic obstructive pulmonary disease, chronic liver disease and cirrhosis, cancer, systemic lupus erythematosus/rheumatoid arthritis/immune disorders, organ transplant, malnutrition, obesity, alcohol abuse, drug abuse and tobacco use disorder were classified into the comorbidity group.

IRR, incidence rate ratio; PY, person-years.

with schizophrenia. The risk of pleural empyema is more than twofold greater than those without schizophrenia. Stratified analyses by age, sex, occupation, income,

Table 4 30-day mortality from pleural empyema in cohorts with and without schizophrenia and OR of mortality

\begin{tabular}{lll}
\hline & \multicolumn{2}{l}{ Schizophrenia } \\
\cline { 2 - 3 } & No & Yes \\
\hline Deaths/events & $6 / 67$ & $11 / 164$ \\
\hline Mortality per 100 & 8.96 & 6.71 \\
\hline $\begin{array}{l}\text { Crude OR }(95 \% \mathrm{Cl}) \\
\text { Adjusted OR* }\end{array}$ & 1 (reference) & $0.73(0.26$ to 2.06$)$ \\
$(95 \% \mathrm{Cl})$ & 1 (reference) & $0.95(0.30$ to 3.01$)$ \\
\hline
\end{tabular}

*Multivariable analysis controlling for age, sex, occupation, income, urbanisation and comorbidities of diabetes, asthma, chronic obstructive pulmonary disease, chronic liver disease and cirrhosis, malnutrition and alcohol abuse. urbanisation and presence of comorbidities also showed that the incidence rates of pleural empyema were consistently higher in the schizophrenia cohort than in comparisons, and the aHRs for pleural empyema associated with schizophrenia were significant for all subgroups. In addition, the incidences of pleural empyema were higher in older people than in young people, higher in men than in women and in individuals with comorbidities than in those without comorbidities. These findings are in accordance with the general concepts.

The mechanism associating schizophrenia with the risk of developing pleural empyema remains largely unknown. Smoking is a well-known behaviour prevalent in patients with schizophrenia and has association with the development of pleural empyema. In addition, an unhealthy lifestyle, lack of self-care, poorer physical circumstances and health-risk activities may contribute to 
this condition. ${ }^{15}$ Frequent medical visits and a prolonged hospital stay may also be contributing factors. ${ }^{18}$ Moreover, patients with schizophrenia may reside in a long-term care facility. Pneumonia in these residents has been defined as a specific type, healthcare-associated pneumonia (HCAP). ${ }^{24}$ The pathogens of HCAP are often multidrug-resistant bacteria, which is a potential risk factor for developing pleural empyema. Furthermore, patients with schizophrenia are at a higher risk of developing swallowing disorders, leading to aspiration pneumonia. ${ }^{25}$ Pleural empyema is easily caused by the aspiration of mixed bacterial flora and other materials from the oropharyngeal cavity and even from the upper gastrointestinal tract. In addition, previous studies have suggested that the use of second-generation antipsychotics, such as clozapine, may increase the risk of pneumonia in patients with schizophrenia. ${ }^{26-28}$ Clozapine has been associated with agranulocytosis, sialorrhea and impaired swallowing function; patients with this medication may thus have a greater risk for pneumonia. ${ }^{29}$

Patients with schizophrenia are at a markedly increased risk of premature death, particularly from thoracic infection and pneumonia. A large-scale study in the USA showed that the overall mortality rate was 3.7 times higher in patients with schizophrenia than in the general population. ${ }^{30}$ The increased mortality was mainly from respiratory diseases: 9.9 times higher from COPD and 7.0 times higher from influenza and pneumonia. A study in Taiwan showed that patients with schizophrenia experienced a 3.09-fold increased risk of developing pneumonia, with an aHR of 1.39 for deaths from pneumonia. ${ }^{16}$ In a Romanian study, autopsy findings in sudden unexpected deaths in inpatients with schizophrenia revealed that the top three specific causes were myocardial infarction $(52.9 \%)$, pneumonia $(11.8 \%)$ and airway obstruction $(7.8 \%) .{ }^{31}$ However, the present study showed no significant disparity in the 30-day mortality between the schizophrenic and comparison cohorts.

The strength of this study was using a large nationwide data to perform the propensity-matched evaluation assessing the pleural empyema risk for patients with schizophrenia. Confounding bias has been thus reduced in this inexpensive retrospective cohort study. The National Health Insurance programme has covered $>99.0 \%$ of the Taiwanese population. The universal health coverage reduces barriers to healthcare access for all citizens, regardless of their socioeconomic background and/or residential location. ${ }^{32}$ The present study reflected a 'realworld' scenario by using the claims data, as schizophrenia, pleural empyema and comorbidities were diagnosed at clinics during medical consultations.

There are several limitations that should be considered when interpreting the study findings. First, we used the ICD-9-CM algorithm to define schizophrenia, pleural empyema and comorbidities. The diagnosis of schizophrenia is mostly accurate because it is a disease with catastrophic certificate. All other diagnoses depended on the competence of clinical physicians. An ad hoc committee established by the insurance authority was in charge of evaluating the claims data to prevent errors and violations. In addition, only the disease with at least two diagnosis codes identified within a year was included to increase the validity and accuracy. Second, the information on smoking, drinking, nutrition and other psychosocial and environmental factors were unavailable, which may affect the risk of pulmonary infections and consequent complications. Instead, we used the tobacco use disorder and alcohol abuse to substitute smoking and drinking, respectively, in the multivariable analysis for adjustment. Similarly, malnutrition is a crucial factor for pleural empyema development; however, it is unlikely to be identified adequately by relying on recorded diagnoses. In addition, institutional residence is a possible source of multiple-resistant infection, but the relevant data were unavailable. Furthermore, other clinical variables such as serum laboratory data, image reports and culture results were not available to our study. ${ }^{33}$

\section{CONCLUSION}

This study provides evidence that patients with schizophrenia are at an elevated risk of developing pleural empyema. The risk increases further for those with comorbidity. Patients with schizophrenia suffering from pneumonia or other thoracic infection need close surveillance for potential risk of development of pleural empyema and disease-related mortality.

\section{Author affiliations}

${ }^{1}$ Division of Pulmonary and Critical Care Medicine, Department of Internal Medicine, China Medical University Hospital, Taichung, Taiwan

${ }^{2}$ Intensive Care Unit, Chu Shang Show Chwan Hospital, Nantou, Taiwan

${ }^{3}$ Department of Psychiatry, China Medical University Hospital, Taichung, Taiwan

${ }^{4}$ Management Office for Health Data, China Medical University Hospital, Taichung,

Taiwan

${ }^{5}$ Department of Business Administration, Asia University, Taichung, Taiwan

${ }^{6}$ School of Medicine, China Medical University, Taichung, Taiwan

${ }^{7}$ Department of Health Services Administration, College of Public Health, China Medical University, Taichung, Taiwan

Contributors T-CS, C-HC, Y-JH, T-CC, C-YT and C-MS conceived and designed the study. T-CH, C-MS and W-HH provided administrative support. T-CS, C-LL, C-MS and F-CS analysed and interpreted the data. T-CS, C-LL, C-MS and F-CS developed and revised the manuscript. All authors were involved in collection and assembly of data. All authors approved the final version of the manuscript to be published.

Funding This study is supported in part by Taiwan Ministry of Health and Welfare Clinical Trial and Research Center of Excellence (MOHW107-TDU-B-212-123004); Academia Sinica Taiwan Biobank Stroke Biosignature Project (BM10501010037); NRPB Stroke Clinical Trial Consortium (MOST 105-2325-B-039-003); China Medical University Hospital (DMR-107-192); Tseng-Lien Lin Foundation, Taichung, Taiwan; Taiwan Brain Disease Foundation, Taipei, Taiwan and Katsuzo and Kiyo Aoshima Memorial Funds, Japan. No additional external funding received for this study.

Disclaimer The funders had no role in study design, data collection and analysis, decision to publish or preparation of the manuscript.

Competing interests None declared.

Patient consent Not required.

Ethics approval This study was approved by the Research Ethics Committee at the China Medical University and Hospital (CMUH-104-REC2-115).

Provenance and peer review Not commissioned; externally peer reviewed. 
Data sharing statement Datasets of National Health Insurance in Taiwan were used. All investigators should sign an agreement that guarantees patient confidentiality before using the data.

Open access This is an open access article distributed in accordance with the Creative Commons Attribution Non Commercial (CC BY-NC 4.0) license, which permits others to distribute, remix, adapt, build upon this work non-commercially, and license their derivative works on different terms, provided the original work is properly cited and the use is non-commercial. See: http://creativecommons.org/ licenses/by-nc/4.0/

C Article author(s) (or their employer(s) unless otherwise stated in the text of the article) 2018. All rights reserved. No commercial use is permitted unless otherwise expressly granted.

\section{REFERENCES}

1. Strange C, Sahn SA. The definitions and epidemiology of pleural space infection. Semin Respir Infect 1999;14:3-8.

2. Sahn SA. Diagnosis and management of parapneumonic effusions and empyema. Clin Infect Dis 2007;45:1480-6.

3. Light RW. Parapneumonic effusions and empyema. Proc Am Thorac Soc 2006;3:75-80.

4. Lai SW, Lin CL, Liao KF. Population-based cohort study investigating the correlation of diabetes mellitus with pleural empyema in adults in Taiwan. Medicine 2017;96:e7763.

5. Lu HY, Liao KM. Risk of empyema in patients with COPD. Int J Chron Obstruct Pulmon Dis 2018;13:317.24.

6. Shen TC, Chen $\mathrm{CH}$, Wang IK, et al. Risk of empyema in patients with end-stage renal disease: a nationwide propensity-matched cohort study. QJM 2017;110:hcx004-30.

7. Ferguson AD, Prescott RJ, Selkon JB, et al. The clinical course and management of thoracic empyema. QJM 1996;89:285-90.

8. Marks DJ, Fisk MD, Koo CY, et al. Thoracic empyema: a 12-year study from a UK tertiary cardiothoracic referral centre. PLoS One 2012;7:e30074.

9. Chen $\mathrm{CH}$, Hsu WH, Chen $\mathrm{HJ}$, et al. Different bacteriology and prognosis of thoracic empyemas between patients with chronic and end-stage renal disease. Chest 2007;132:532.9.

10. Chen $\mathrm{CH}$, Shih CM, Chou JW, et al. Outcome predictors of cirrhotic patients with spontaneous bacterial empyema. Liver Int 2011;31:417.24.

11. World Health Organization. Schizophrenia. http://www.who.int/ mental_health/management/schizophrenia (accessed 21 Mar 2018).

12 . Diagnostic and Statistical Manual of Mental Disorders (DSM-5). https://www.psychiatry.org/psychiatrists/practice/dsm (accessed 21 Mar 2018).

13. van Os J, Kapur S. Schizophrenia. Lancet 2009;374:635-45.

14. Saha S, Chant D, McGrath J. A systematic review of mortality in schizophrenia: is the differential mortality gap worsening over time? Arch Gen Psychiatry 2007;64:1123-31.

15. Seminog OO, Goldacre MJ. Risk of pneumonia and pneumococcal disease in people with severe mental illness: English record linkage studies. Thorax 2013;68:171-6.
16. Chou FH, Tsai KY, Chou YM. The incidence and all-cause mortality of pneumonia in patients with schizophrenia: a nine-year follow-up study. J Psychiatr Res 2013;47:460-6.

17. Copeland LA, Mortensen EM, Zeber JE, et al. Pulmonary disease among inpatient decedents: Impact of schizophrenia. Prog Neuropsychopharmacol Biol Psychiatry 2007;31:720-6.

18. Schoepf D, Uppal H, Potluri R, et al. Physical comorbidity and its relevance on mortality in schizophrenia: a naturalistic 12-year followup in general hospital admissions. Eur Arch Psychiatry Clin Neurosci 2014;264:3-28.

19. Chen $\mathrm{YH}$, Lin HC, Lin HC. Poor clinical outcomes among pneumonia patients with schizophrenia. Schizophr Bull 2011;37:1088.94.

20. Hsu JH, Chien IC, Lin CH, et al. Increased risk of chronic obstructive pulmonary disease in patients with schizophrenia: a populationbased study. Psychosomatics 2013;54:345-51.

21. Lee CB, Li CY, Lin CM. Medical Resource Utilization by Taiwanese Psychiatric Inpatients under the National Health Insurance System. $J$ Ment Health Policy Econ 2016;19:193-9.

22. Shen TC, Chen $\mathrm{CH}$, Lai HC, et al. Risk of empyema in patients with chronic liver disease and cirrhosis: A nationwide, population-based cohort study. Liver Int 2017;37:862-70.

23. Austin PC. Balance diagnostics for comparing the distribution of baseline covariates between treatment groups in propensity-score matched samples. Stat Med 2009;28:3083-107.

24. American Thoracic Societylnfectious Diseases Society of America. Guidelines for the management of adults with hospital-acquired, ventilator-associated, and healthcare-associated pneumonia. Am J Respir Crit Care Med 2005;171:388-416.

25. Kulkarni DP, Kamath VD, Stewart JT. Swallowing Disorders in Schizophrenia. Dysphagia 2017;32:467-71.

26. Kuo CJ, Yang SY, Liao YT, et al. Second-generation antipsychotic medications and risk of pneumonia in schizophrenia. Schizophr Bull 2013;39:648-57.

27. Hung GC, Liu HC, Yang SY, et al. Antipsychotic reexposure and recurrent pneumonia in schizophrenia: a nested case-control study. $J$ Clin Psychiatry 2016;77:60-6.

28. Gurrera RJ, Parlee AC, Perry NL. Aspiration Pneumonia: An Underappreciated Risk of Clozapine Treatment. J Clin Psychopharmacol 2016;36:174-6.

29. Stoecker ZR, George WT, O'Brien JB, et al. Clozapine usage increases the incidence of pneumonia compared with risperidone and the general population: a retrospective comparison of clozapine, risperidone, and the general population in a single hospital over 25 months. Int Clin Psychopharmacol 2017;32:155-60.

30. Olfson M, Gerhard T, Huang C, et al. Premature Mortality Among Adults With Schizophrenia in the United States. JAMA Psychiatry 2015;72:1172-81.

31. Ifteni P, Correll CU, Burtea V, et al. Sudden unexpected death in schizophrenia: autopsy findings in psychiatric inpatients. Schizophr Res 2014:155:72-6.

32. Hsing AW, loannidis JP. Nationwide Population Science: Lessons From the Taiwan National Health Insurance Research Database. JAMA Intern Med 2015;175:1527-9.

33. Shen TC, Lin CY, Lin CL, et al. Risk of developing pleural empyema in patients with stroke: a propensity-matched cohort study. Intern Emerg Med 2017;12:1131-8. 